MORAES, G.V. et al. Desenvolvimento corporal, avaliações de carcaça e lipedimia de caprinos machos alimentados com grão de linhaça na dieta. PUBVET, Londrina, V. 8, N. 10, Ed. 259, Art. 1718, Maio, 2014.

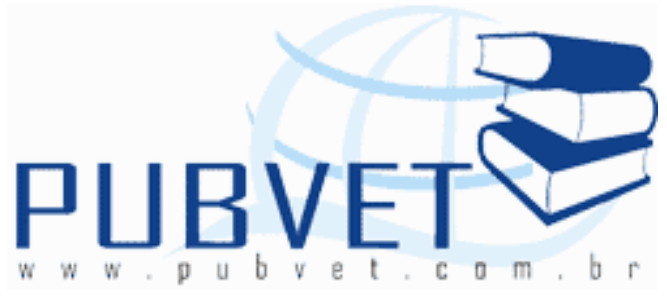

PUBVET, Publicações em Medicina Veterinária e Zootecnia.

\title{
Desenvolvimento corporal, avaliações de carcaça e lipedimia de caprinos machos alimentados com grão de linhaça na dieta
}

Gentil Vanini de Moraes*1, Egon José Fück ${ }^{2}$, Marco Antonio Bensimon Gomes ${ }^{3}$,

Francisco de Assis Fonseca de Macedo ${ }^{4}$, Pedro Luiz Castro ${ }^{5}$, Marcela Mataveli ${ }^{6}$

${ }^{1}$ Médico Veterinário, PhD. Professor do Departamento de Zootecnia - Universidade Estadual de Maringá - Maringá PR.

${ }^{2}$ Médico Veterinário, PhD. Diretor clínico do Hospital Veterinário SOS AnimalMaringá PR.

${ }^{3}$ Zootecnista, PhD. Professor da UniCesumar - Maringá PR.

${ }^{4}$ Zootecnista, PhD. Professor do Departamento de Zootecnia - Universidade Estadual de Maringá - Maringá PR.

${ }^{5}$ Zootecnista, Mestrando Universidade Estadual de Maringá - Maringá PR.

${ }^{6}$ Zootecnista, PhD. Embrapa CNPASA - Palmas TO.

*Autor para correspondência - E-mail: gvmoraes@uem.br

\section{Resumo}

Objetivou-se avaliar a inclusão de grãos de linhaça (Linum usitatissimum) na dieta de caprinos sobre o desenvolvimento corporal, características bioquímicas sanguíneas e características da carcaça de caprinos das raças Bôer e Anglonubiano. Foram divididos, aleatoriamente, 12 animais de duas raças, 
MORAES, G.V. et al. Desenvolvimento corporal, avaliações de carcaça e lipedimia de caprinos machos alimentados com grão de linhaça na dieta. PUBVET, Londrina, V. 8, N. 10, Ed. 259, Art. 1718, Maio, 2014.

confinados, submetidos à dieta com 9,5\% de grãos de linhaça e dieta controle. Dos 4 aos 12 meses de idade, os animais foram avaliados quanto ao desenvolvimento corporal, ganho de peso, conversão alimentar, rendimento de carcaça, níveis sanguíneos de triglicerídeos, colesterol e frações, e no músculo Longissimus dorsi avaliou-se, gordura total, ômega $(\omega) 3, \omega$, gorduras saturadas, ácidos graxos poliinsaturadas, razão $\omega 6: \omega 3$ e a razão gorduras saturadas/poliinsaturadas. As variáveis foram analisadas pela metodologia de BootStrap. Com exceção dos triglicerídeos e VLDL (lipoproteína de muito baixa densidade), que aumentaram $(P<0,05)$, nas demais características não houve diferenças $(P>0,05)$. Conclui-se que o uso de grãos de linhaça não influenciou o desenvolvimento corporal, as variáveis bioquímicas e as características das carcaças de caprinos.

Palavras-chave: ácidos graxos poliinsaturados, lipidograma, ômega 3, produção de carne, qualidade da carcaça, qualidade da carne

\title{
Body development, carcass evaluations and lipidimia in male goats feed with linseed in the diet
}

\begin{abstract}
The study was carried out with objective to evaluate the effects of whole linseed addition in the diet of male goats on the development, blood and biochemical characteristics and on the Boer and Anglo-nubian males carcass. They were randomly divided in two groups balanced by breed, confined and submitted to diet with $9.5 \%$ of whole linseed and a control diet. The animals were observed from 4 to 12 months old and were evaluated on the body development, carcass yielding, feeding conversion, weight gain, biochemical levels of triglycerides, cholesterol and fractions, and on Longissimus dorsi muscle total fat, omega $(\omega) 3$, $\omega-6$, saturated fats, unsaturated fatty acids, $\omega-6 / \omega-3$ ratio,
\end{abstract}


MORAES, G.V. et al. Desenvolvimento corporal, avaliações de carcaça e lipedimia de caprinos machos alimentados com grão de linhaça na dieta. PUBVET, Londrina, V. 8, N. 10, Ed. 259, Art. 1718, Maio, 2014.

saturated/unsaturated fats ratio were analyzed. The variables were analyzed by the BootStrap methodology. All the variables, with exception of triglycerides levels and Very-low-density lipoprotein (VLDL), did not present differences $(P>0.05)$. So it was concluded that whole linseed addition in the male goat diet did not promote improvement in the body development, blood biochemical variables and characteristics of carcasses.

Keywords: carcass quality, fatty acid of carcass, lipidogram, meat quality, meat production, omega-3

\section{Introdução}

As recentes descobertas em saúde humana vêm, mudando os conceitos e os hábitos alimentares. As mudanças se referem à redução da ingestão de gorduras presentes no leite e derivados, e na carne de ruminantes, pela presença de ácidos graxos saturados, o que contribui para o desenvolvimento de doenças cardiovasculares (Willians, 2000). Sanz et al. (2000) afirmaram que a presença do ácido linoléico, na dieta, reduz a deposição de gordura abdominal e diminui a atividade de algumas enzimas lipogênicas. Modesto et al. (2002) recomendaram a ingestão de omega 3 por ser antioxidante, elemento que protege o sistema cardiovascular, favorece o desenvolvimento dos tecidos nervoso e da visão.

Os ácidos linoléico (C18:2) e linolênico (C18:3) estão presentes, em abundância, em óleos vegetais como o de girassol, canola, soja e linhaça (Demeyer \& Doreau, 1999). Os mesmos autores verificaram ainda que a concentração de ácidos graxos linoléico e linolênico se eleva nos tecidos marcadamente quando bovinos são alimentados com dietas ricas em sementes ou óleos com alto teor destes ácidos graxos.

Mir et al. (2000), Geay et al. (2001) e Ludovico (2002) revelaram a importância dos ácidos graxos no metabolismo dos mamíferos, especialmente alguns ácidos graxos poliinsaturados, como o linoléico $(\omega 6)$ e seus derivados, que 
MORAES, G.V. et al. Desenvolvimento corporal, avaliações de carcaça e lipedimia de caprinos machos alimentados com grão de linhaça na dieta. PUBVET, Londrina, V. 8, N. 10, Ed. 259, Art. 1718, Maio, 2014.

formam a família dos ácidos graxos ômega-6 e, principalmente, o ácido graxo linolênico $(\omega 3)$ e seus derivados que formam a família dos ácidos graxos ômega3, presentes em óleos vegetais.

É necessário, portanto, a realização de pesquisas nesta área, orientando a oferta de carne de caprinos em quantidade e qualidade, visando não apenas oferecer características sensoriais agradáveis ao consumidor, como também proporcionar um alimento saudável e benéfico (Madruga et al., 1999), como carcaças com ácidos graxos poliinsaturados (Modesto et al., 2002).

Em humanos, os nutricionistas estão recomendando menor ingestão de gordura total e maior ingestão de ácidos graxos poliinsaturados (AGPI), especialmente, $\omega-3$ e/ou $\omega-6$ (USDA, 1998; Voedingsaanbevelingen, 2000) e a relação dietética de $\omega 6 / \omega 3$ menor que cinco e a relação ácidos graxos poliinsaturados/ácidos graxos saturados maior que 0,7 (Raes et al., 2004).

A linhaça apresenta uma composição média de $350 \mathrm{~g}$ de gordura/kg de material fresco, dos quais $53 \%$ dos ácidos graxos são $\omega-3$ e baixa razão $\omega-6 / \omega-3$.

No rúmen, ocorre biohidrogenação de grande quantidade de ácidos graxos insaturados da dieta, formando lipídios saturados e ácidos graxos transmonoinsaturados que se depositam nos tecidos desses animais (Demeyer \& Doreau, 1999). Contudo, de acordo com Mattos et al. (2000), certa proporção de ácidos graxos insaturados não sofre biohidrogenação completa e pode passar para o duodeno. Para Jenkins (1993), 86,6\% a 95,3 \% dos ácidos graxos poliinsaturados são biohidrogenados pelos microrganismos ruminais até ácidos graxos menos insaturados.

Este trabalho foi realizado com o objetivo de avaliar o desenvolvimento corporal, níveis sangüíneos de colesterol e frações, rendimento de carcaça e perfil de ácidos graxos no músculo Longissimus dorsi, em caprinos terminados em confinamento, com dietas com e sem sementes de linhaça. 
MORAES, G.V. et al. Desenvolvimento corporal, avaliações de carcaça e lipedimia de caprinos machos alimentados com grão de linhaça na dieta. PUBVET, Londrina, V. 8, N. 10, Ed. 259, Art. 1718, Maio, 2014.

\section{Material e Métodos}

O trabalho foi desenvolvido no setor de caprinocultura da Fazenda Experimental da Universidade Estadual de Maringá, em Iguatemi, distrito de Maringá/PR.

Doze animais Anglonubiano e Bôer foram identificados e distribuídos conforme peso inicial que variou de 18,28 e 19,30 kg, sendo confinados e arraçoados com dietas elaboradas de acordo com as exigências nutricionais dos animais (NRC, 1981), e analisadas pelo laboratório de Nutrição Animal da Universidade Estadual de Maringá (LANA) de acordo com as descrições de Silva (1990). Foram divididos em dois grupos de seis animais com três animais de cada grupo racial. O grupo controle recebeu dieta sem grãos de linhaça (Linum usitatissimum) e outro com $9,5 \%$ de grãos de linhaça na matéria seca (MS), que proporcionaram $2,30 \%$ e $5,78 \%$ de extrato etéreo (EE) para os grupos controle e linhaça, respectivamente (Tabela 1 ).

Os animais tiveram um período de adaptação com a dieta controle por um mês, tendo o experimento sido realizado de Dezembro de 2004 a Junho de 2005.

Foram realizadas as análises das dietas experimentais para determinar a composição dos principais ácidos graxos (Tabela 2).

A partir do início do experimento, mensalmente, os animais foram pesados e verificados o consumo da dieta. Uma vez por mês foi coletado sangue, por venopunção da veia jugular, com agulha hipodérmica 40×12 em tubos de ensaio para avaliação dos teores de triglicerídeos, colesterol e frações. Após a coleta, o sangue foi imediatamente centrifugado a $3000 \mathrm{rpm}(1600 \mathrm{~g})$ por 15 minutos, em temperatura ambiente. Depois de obtido o soro, as amostras foram congeladas a $-18^{\circ} \mathrm{C}$ até a realização das análises de triglicerídeos, colesterol e HDL (High Density Lipoprotein) pelo método enzimático colorimétrico, utilizando o aparelho Bioplus 200 com Led (Bioplus $^{\circledR}$ ) e o kit da Labtest ${ }^{\circledR}$. O VLDL (Very Low Density Lipoprotein) e LDL (Low Density Lipoprotein), foram calculados pela equação de 
MORAES, G.V. et al. Desenvolvimento corporal, avaliações de carcaça e lipedimia de caprinos machos alimentados com grão de linhaça na dieta. PUBVET, Londrina, V. 8, N. 10, Ed. 259, Art. 1718, Maio, 2014.

Friedewald. O VLDL correspondeu os triglicerídeos divididos por cinco e o LDL a soma do HDL com VLDL.

TABELA 1. Composição das dietas experimentais (\%MS)

\begin{tabular}{llc}
\hline & \multicolumn{2}{c}{ Rações experimentais } \\
\cline { 2 - 3 } Item & Controle
\end{tabular}

\section{Ingrediente:}

Feno de aveia

35,00

35,00

Milho moído

44,00

37,40

Farelo de soja

16,70

13,80

Calcário

0,70

0,70

Suplemento Mineral *

3,00

3,00

Fosfato bicálcico

0,60

0,60

Semente de linhaça

9,50

\section{Composição química:}

Matéria seca

92,00

88,16

Proteína Bruta

15,19

15,38

Extrato Etéreo

2,30

5,78

Fibra detergente neutro

30,28

31,45

Matéria mineral

4,30

4,30

Nutrientes digestíveis totais

67,51

68,37

* Caprinophós ${ }^{\circledR}$ - Tortuga- Níveis de garantia/Kg: Vitamina A 35.000,00 UI.; Vitamina D3 68.000,00 UI; Vitamina E 450,00 UI; Cálcio 240,00 g; Fósforo 71,00 g; Potássio 28,20 g; Enxofre 20,00 g; Magnésio 20,00 g; Cobre 400,00 mg; Cobalto 30,00 mg; Cromo 10,00 mg; Ferro 2.500,00 mg; Iodo 40,00 mg; Manganês 1.350,00 mg; Selênio 15,00 mg; Zinco 1.700,00 mg; Flúor (Máx.) 710,00 mg; Solubilidade do Fósforo (P) em Ácido Cítrico A 2\% (Min.) 95\% 
MORAES, G.V. et al. Desenvolvimento corporal, avaliações de carcaça e lipedimia de caprinos machos alimentados com grão de linhaça na dieta. PUBVET, Londrina, V. 8, N. 10, Ed. 259, Art. 1718, Maio, 2014.

TABELA 2. Teores médios dos principais ácidos graxos das dietas experimentais

\begin{tabular}{lcc}
\hline \multirow{2}{*}{ Parâmetros } & \multicolumn{2}{c}{$(\%)$} \\
\cline { 2 - 3 } & Controle & Linhaça \\
\hline Extrato Etéreo & 2,30 & 5,78 \\
Ômega 3 $(\omega-3)$ & 0,91 & 3,81 \\
Ômega 6 $(\omega-6)$ & 18,34 & 16,27 \\
Razão $\omega-6: \omega-3$ & 20,15 & 4,27 \\
\hline
\end{tabular}

Aos 12 meses de idade, os animais foram pesados para obtenção do peso vivo ao abate e abatidos após permanecerem 18 horas sob dieta exclusivamente hídrica. Em seguida, o aparelho digestório foi retirado e esvaziado para a obtenção do peso corporal vazio calculado pela diferença do peso vivo ao abate e o peso do conteúdo gastroentérico, visando determinar o rendimento verdadeiro que é a relação entre o peso da carcaça quente e o peso corporal vazio (Sañudo \& Sierra, 1986).

Terminada a evisceração, as carcaças foram pesadas e transferidas para uma câmara fria a $4^{\circ} \mathrm{C}$, permanecendo por 24 horas, penduradas pelos tendões, em ganchos apropriados. Após o estabelecimento do rigor mortis, foi realizado o corte transversal e retiradas amostras do músculo Longissimus dorsi entre a $12^{a}$ e $13^{a}$ costelas, juntamente com a gordura de cobertura, as quais foram acondicionadas em embalagens de papel aluminado e armazenadas a $18^{\circ} \mathrm{C}$ até $\mathrm{o}$ início das análises. Para as análises no Laboratório de alimentos do Departamento de Química da Universidade Estadual de Maringá, as amostras triplicadas do Longissimus dorsi foram descongeladas em temperatura ambiente e, em seguida, trituradas em processador de alimentos, sendo devidamente homogeneizadas em gral de porcelana (Kinssela et al., 1977).

Para análise do teor de lipídeos na carcaça foi utilizado o método de Kinsella et al. (1977). A descrição desta metodologia consistiu na extração dos 
MORAES, G.V. et al. Desenvolvimento corporal, avaliações de carcaça e lipedimia de caprinos machos alimentados com grão de linhaça na dieta. PUBVET, Londrina, V. 8, N. 10, Ed. 259, Art. 1718, Maio, 2014.

lipídeos da emulsão, e após foram submetidos aos processos de hidrólise e esterificação. Após o resfriamento das amostras, os ésteres metílicos de ácidos graxos (EMAG) foram analisados por cromatografia gasosa, utilizando-se cromatógrafo a gás CGS 14 - A Shimadzu CG, equipado com detector de ionização de chama e coluna capilar de sílica fundida (100 m de comprimento, $0,25 \mu \mathrm{m}$ de CP - Sil88, ChromPack). A identificação dos picos cromatográficos das amostras foi realizada por meio de seu respectivo tempo de retenção, com padrões dos ésteres metílicos. A quantificação dos picos cromatográficos foi efetuada com Integrador-processador CG 300 acoplado ao cromatógrafo, sendo a quantidade de amostra injetada equivalente à área total dos picos, e os resultados expressos em percentagens dos ácidos graxos (AG) encontrados, em relação ao total dos $A G$ presentes na matéria graxa.

O delineamento experimental foi o inteiramente casualizado, utilizando a análise de BootStrap (Efron \& Tishirani, 1993; Davison \& Hinkley, 1997). Foi aplicado o Teste $t$ para verificação de igualdade de médias dos dados e o Teste $F$ para verificação de igualdade de variância dos dados $(P<0,05)$.

\section{Resultados e Discussão}

As médias encontradas para as variáveis bioquímicas foram de 64,38 e $72,3 \mathrm{mg} / \mathrm{dL}$ de sangue para colesterol; de 24,37 e $32,48 \mathrm{mg} / \mathrm{dL}$ para triglicerídeos; de 41,42 e 40,71 mg/dL para $\mathrm{HDL}$; de 22,96 e 28,41 mg/dL para LDL; de 4,91 e 6,00 mg/dL para VLDL, nos grupos controle e linhaça, respectivamente (Tabela 3 ). Os resultados mostraram efeitos significativos $(P<0,05)$ das dietas sobre os triglicerídeos e o VLDL e, as demais, sem diferença estatística $(P>0,05)$. Os teores de colesterol, mesmo não diferindo estatisticamente, encontraram-se em níveis médios de $68 \mathrm{mg} / \mathrm{dL}$ de sangue, teor similar aos 57,76 mg/dL encontrados por Rowe et al. (1999), em ovinos. 
MORAES, G.V. et al. Desenvolvimento corporal, avaliações de carcaça e lipedimia de caprinos machos alimentados com grão de linhaça na dieta. PUBVET, Londrina, V. 8, N. 10, Ed. 259, Art. 1718, Maio, 2014.

TABELA 3 - Análise das variáveis médias observadas e intervalos de confiança médio Bootstrap para a diferença de médias dos dados das variáveis bioquímicas obtidas do sangue de caprinos tratados com grão de linhaça e controle

\begin{tabular}{|c|c|c|c|c|c|c|}
\hline $\begin{array}{l}\text { Variáveis } \\
\text { (mg/dL) }\end{array}$ & G & $\mu$ & $\mathrm{IC}(\mu ; 95 \%)$ & DP & IC(DP;95\%) & $\begin{array}{c}\text { IC Bootstrap } \\
(95 \%)^{1}\end{array}$ \\
\hline \multirow[t]{3}{*}{ CT } & C & 64,38 & $(56,94 ; 71,81)$ & 7,08 & $(4,42 ; 17,38)$ & \\
\hline & $\mathrm{L}$ & 72,30 & $(48,58 ; 96,01)$ & 22,59 & $(14,10 ; 55,42)$ & \\
\hline & D & $-7,92$ & $(-29,46 ; 13,62)$ & 16,74 & $(11,70 ; 29,39)$ & $(-25,50 ; 8,86)$ \\
\hline \multirow[t]{3}{*}{ Triglicerídeos } & C & 24,57 & $(21,07 ; 28,07)$ & 3,33 & $(2,08 ; 8,18)$ & \\
\hline & $L$ & 32,48 & $(25,23 ; 39,74)$ & 6,91 & $(4,31 ; 16,95)$ & \\
\hline & D & $-7,91$ & $(-14,90 ;-0,93)$ & 5,42 & $(3,79 ; 9,52)$ & $(-13,6 ; 2,4)^{* *}$ \\
\hline \multirow[t]{3}{*}{ CT HDL } & C & 41,42 & $(39,77 ; 43,08)$ & 1,57 & $(0,98 ; 3,86)$ & \\
\hline & $L$ & 40,71 & $(34,12 ; 47,30)$ & 6,28 & $(3,92 ; 15,40)$ & \\
\hline & D & 0,71 & $(-5,18 ; 6,60)$ & 4,57 & $(3,19 ; 8,03)$ & $(-4,20 ; 5,19)$ \\
\hline \multirow[t]{3}{*}{ CT LDL } & C & 22,96 & $(8,42 ; 37,50)$ & 13,85 & $(8,64 ; 33,98)$ & \\
\hline & $L$ & 28,41 & $(12,37 ; 44,44)$ & 15,27 & $(9,53 ; 37,47)$ & \\
\hline & D & $-5,44$ & $(-24,20 ; 13,31)$ & 14,58 & $(10,19 ; 25,59)$ & $(-19,97 ; 10,26)$ \\
\hline \multirow[t]{3}{*}{ CT VLDL } & C & 4,91 & $(4,22 ; 5,59)$ & 0,65 & $(0,40 ; 1,60)$ & \\
\hline & L & 6,70 & $(4,77 ; 8,63)$ & 1,83 & $(1,14 ; 4,51)$ & \\
\hline & D & $-1,78$ & $(-3,56 ;-0,01)$ & 1,38 & $(0,96 ; 2,42)$ & $(-3,3 ;-0,5)^{* *}$ \\
\hline
\end{tabular}

${ }^{1}$ - Quando significativo, o valor é identificado com **. Bootstrap $=10000$ reamostragens.

$\mu=$ média; DP = Desvio Padrão; IC = Intervalo de confiança; $C T=$ colesterol total; $C=$ controle; $L=$ linhaça; $\mathrm{D}=$ diferença; $\mathrm{G}=$ grupo. 
MORAES, G.V. et al. Desenvolvimento corporal, avaliações de carcaça e lipedimia de caprinos machos alimentados com grão de linhaça na dieta. PUBVET, Londrina, V. 8, N. 10, Ed. 259, Art. 1718, Maio, 2014.

Observou-se efeito significativo nos teores de triglicerídeos e VLDL $(P<0,05)$, o que é compatível com dietas com níveis elevados de gordura. $O$ papel dos quilomicrons é transportar os ácidos graxos da dieta como triglicerídeos para tecidos para estocagem como gordura (Bauchart, 1993).

A secreção de quilomicrons é estimulada pelo incremento na gordura na dieta ou ácidos graxos poliinsaturados, comparado com ácidos graxos saturados, que em ovelhas, como em ratos e humanos leva a uma maior secreção de partículas de VLDL pelas células da mucosa intestinal (Harrison, et al., 1974). Também, Zain (2004), verificou que a associação mais comum dos ácidos graxos com tecido adiposo está relacionada a sua estocagem como triglicerídeos em adipócitos maduros e a conseqüência do excesso provoca a obesidade.

Os dados diferem dos achados de Velásquez et al.(1996) que, trabalhando com fêmeas caprinas alimentadas com rações hiperlipídicas verificaram aumento nas concentrações séricas de colesterol total e de colesterol HDL.

Neste trabalho, utilizou-se o grão de linhaça integral, porém Scislowski et al. (2005) relataram que os valores de colesterol aumentaram durante a administração de dietas ricas em AGPI infundido no duodeno, visando proteger da hidrogenação bacteriana ruminal.

As médias encontradas de peso inicial foram de 18,28 e 19,30 kg, para peso final de 37,11 e 39,40 kg, para ganho de peso total de 18,83 e 20,10 kg, para peso de carcaça de 17,87 e $18,40 \mathrm{~kg}$ e de 48,81 e 46,29\% para rendimento de carcaça nos grupos controle e linhaça, respectivamente (Tabela 4), não havendo diferenças $(P>0,05)$.

O rendimento médio de carcaça, considerando-se as dietas foi de $47,52 \%$ que pode ser considerado bom sendo equivalente àqueles registrados por Alves et al. (2002), Reis et al. (2001) e Yamamoto (2003). Glimp (1995) reportou que ao comparar caprinos com outros animais domésticos, aqueles, geralmente, 
MORAES, G.V. et al. Desenvolvimento corporal, avaliações de carcaça e lipedimia de caprinos machos alimentados com grão de linhaça na dieta. PUBVET, Londrina, V. 8, N. 10, Ed. 259, Art. 1718, Maio, 2014.

apresentam baixa produção de carcaça, mas com alto conteúdo de carne e baixo teor de gordura.

TABELA 4. Análise das variáveis observadas e intervalos de confiança Bootstrap para a diferença média dos dados de avaliação de peso e rendimento de carcaça obtidas de caprinos tratados com grão de linhaça e controle

\begin{tabular}{lcccccc}
\hline Variáveis & G & $\mu$ & IC $(\mu ; 95 \%)$ & DP & IC $(D P ; 95 \%)$ & $\begin{array}{c}\text { IC Bootstrap } \\
(95 \%)^{1}\end{array}$ \\
\hline Peso inicial(kg) & C & 18,28 & $(13,8 ; 22,76)$ & 4,27 & $(2,66 ; 10,47)$ & \\
& L & 19,30 & $(12,87 ; 25,72)$ & 6,12 & $(3,82 ; 15,02)$ & \\
Peso final $(\mathrm{kg})$ & D & $-1,02$ & $(-7.81 ; 5.78)$ & 5.28 & $(3.69 ; 9.27)$ & $(-6.62 ; 4.28)$ \\
& C & 37,11 & $(29,68 ; 44,55)$ & 7,08 & $(4,42 ; 17,38)$ & \\
Ganho de peso(kg) & L 39,40 & $(31,34 ; 47,44)$ & 7,66 & $(4,78 ; 18,80)$ & \\
& D & $-2,28$ & $(-11,78 ; 7,21)$ & 7,38 & $(5,15 ; 12,95)$ & $(-9,93 ; 5,11)$ \\
& C & 18,83 & $(13,58 ; 24,07)$ & 4,99 & $(3,12 ; 12,26)$ & \\
Peso carcaça(kg) & L & 20,10 & $(13,69 ; 26,51)$ & 6,10 & $(3,81 ; 14,98)$ & \\
& D & $-1,26$ & $(-8,44 ; 5,91)$ & 5,58 & $(3,89 ; 9,79)$ & $(-7,10 ; 4,28)$ \\
& C & 17,87 & $(15,50 ; 20,23)$ & 2,25 & $(1,40 ; 5,52)$ & \\
Rendimento carcaça(\%) & C 48,81 & $(44,09 ; 53,53)$ & 4,49 & $(2,80 ; 11,03)$ & \\
& L & 18,14 & $(14,86 ; 21,42)$ & 3,12 & $(1,95 ; 7,67)$ & \\
& D & $-0,27$ & $(-3,78 ; 3,23)$ & 2,72 & $(1,90 ; 4,78)$ & $(-3,02 ; 2,51)$ \\
& D & 2,52 & $(-2,19 ; 7,23)$ & 3,66 & $(2,56 ; 6,43)$ & $(-0,96 ; 6,52)$ \\
\hline
\end{tabular}

${ }^{1}$ - Quando significativo, o valor é identificado com **. B=10000 reamostragens.

$\mu=$ média; $\mathrm{DP}=$ Desvio Padrão; IC = Intervalo de confiança; $C=$ controle; $L=$ linhaça; $D=$ diferença; $G=$ grupo 
MORAES, G.V. et al. Desenvolvimento corporal, avaliações de carcaça e lipedimia de caprinos machos alimentados com grão de linhaça na dieta. PUBVET, Londrina, V. 8, N. 10, Ed. 259, Art. 1718, Maio, 2014.

Wilkinson \& Stark (1987) observaram que o rendimento de carcaças caprinas em relação à carne/músculo, situa-se, geralmente, na faixa de $45 \%$ a $52 \%$ do peso vivo do animal, podendo alcançar taxas de até $68 \%$. Segundo estes autores estas taxas de rendimento resultam do fato de que o desenvolvimento de gordura na carcaça caprina ocorre muito tardiamente, não alcançando níveis apreciáveis até que o peso do animal atinja $40 \mathrm{~kg}$ ou mais. Isto foi verificado neste trabalho, pois os animais abatidos encontravam-se com peso médio de 37,11 e $39,40 \mathrm{~kg}$ para os grupos controle e linhaça, respectivamente.

Os ganhos de peso médio diários foram abaixo dos encontrados por Zeoula (2002), que avaliou o desempenho de cordeiros da raça Morada Nova, não castrados, com peso vivo médio inicial de $15 \mathrm{~kg}$, distribuídos em três dietas com diferentes relações concentrado:volumoso $(60: 40 ; 45: 55 ; 30: 70)$, com níveis energéticos de 4,46; 4,41 e 4,37 Mcal EB/kg de MS, respectivamente. Esta autora, obteve os ganhos médios diários de $0,172 \mathrm{~kg}, 0,107 \mathrm{~kg}$ e 0,038 kg, para as respectivas relações concentrado:volumoso. Neste trabalho, obteve-se uma média de 0,082 $\mathrm{Kg} /$ dia na relação concentrado:volumoso de $65: 35$, porém, os animais foram manejados duas vezes por semana para coleta de sêmen, o que pode ter interferido numa melhor performance devido ao estresse causado. Naudé \& Hofmeyer (1981) afirmam de que os caprinos machos, quando não castrados, ao atingirem a puberdade ( 5 a 6 meses) reduzem a taxa de crescimento e podem até mesmo perder peso devido ao estímulo sexual.

As médias de gorduras totais encontradas na avaliação das carcaças foram de 1,84 e 2,07\% ; de 2,54\% e 2,13\%, para níveis de ômega 3 ; de 4,71\% e 4,78\%, para ômega 6; de 7,52\% e 7,20\%, para os níveis de AGPI; de 35,96\% e $37,68 \%$ para os níveis de AGS; de $0,21 \%$ e $0,19 \%$, para a relação AGPI/AGS e de 1,96 e 2,23 para a razão ômega6/ômega3 nos grupos controle e linhaça, respectivamente (Tabela 5 ). 
MORAES, G.V. et al. Desenvolvimento corporal, avaliações de carcaça e lipedimia de caprinos machos alimentados com grão de linhaça na dieta. PUBVET, Londrina, V. 8, N. 10, Ed. 259, Art. 1718, Maio, 2014.

TABELA 5. Análise das variáveis observadas e intervalos de confiança Bootstrap para a diferença média dos dados de avaliação das gorduras totais das carcaças de caprinos tratados com grão de linhaça e controle

\begin{tabular}{|c|c|c|c|c|c|c|}
\hline Variáveis (\%) & $\mathrm{G}$ & $\mu$ & $\mathrm{IC}(\mu ; 95 \%)$ & $\mathrm{DP}$ & IC(DP;95\%) & $\begin{array}{c}\text { IC } \\
\text { Bootstrap }(95 \%)\end{array}$ \\
\hline \multirow[t]{3}{*}{ Lipídios totais } & C & 1,84 & $(1,54 ; 2,13)$ & 0,27 & $(0,17 ; 0,68)$ & \\
\hline & L & 2,07 & $(1,62 ; 2,52)$ & 0,42 & $(0,26 ; 1,05)$ & \\
\hline & D & $-0,23$ & $(-0,70 ; 0,22)$ & 0,36 & $(0,25 ; 0,63)$ & $(-0,60 ; 0,12)$ \\
\hline \multirow[t]{3}{*}{$\omega 3$} & C & 2,54 & $(1,78 ; 3,30)$ & 0,72 & $(0,45 ; 1,77)$ & \\
\hline & L & 2,13 & $(1,73 ; 2,54)$ & 0,38 & $(0,23 ; 0,94)$ & \\
\hline & $D$ & 0,40 & $(-0,33 ; 1,15)$ & 0,57 & $(0,40 ; 1,01)$ & $(-0,16 ; 0,99)$ \\
\hline \multirow[t]{3}{*}{$\omega 6$} & C & 4,71 & $(3,46 ; 5,96)$ & 1,18 & $(0,74 ; 2,91)$ & \\
\hline & L & 4,78 & $(3,73 ; 5,84)$ & 1,00 & $(0,62 ; 2,46)$ & \\
\hline & $D$ & $-0,07$ & $(-1,48 ; 1,34)$ & 1,10 & $(0,76 ; 1,93)$ & $(-1,18 ; 1,04)$ \\
\hline \multirow[t]{3}{*}{ AGPI } & $\mathrm{C}$ & 7,52 & $(5,42 ; 9,61)$ & 1,99 & $(1,24 ; 4,90)$ & \\
\hline & L & 7,20 & $(5,69 ; 8,71)$ & 1,43 & $(0,89 ; 3,52)$ & \\
\hline & $D$ & 0,318 & $(-1,92 ; 2,55)$ & 1,74 & $(1,21 ; 3,05)$ & $(-1,43 ; 2,11)$ \\
\hline \multirow[t]{3}{*}{ AGS } & C & 35,96 & $(34,59 ; 37,34$ & 1,31 & $(0,81 ; 3,21)$ & \\
\hline & L & 37,68 & $(34,39 ; 40,97)$ & 3,13 & $(1,95 ; 7,66)$ & \\
\hline & D & $-1,71$ & $(-4,81 ; 1,37)$ & 2,40 & $(1,68 ; 4,22)$ & $(-4,15 ; 0,80)$ \\
\hline \multirow[t]{3}{*}{ AGPI/AGS } & C & 0,21 & $(0,19 ; 024)$ & 0,04 & $(0,02 ; 0,06)$ & \\
\hline & $\mathrm{L}$ & 0,19 & $(0,16 ; 0,21)$ & 0,02 & $(0,01 ; 0,05)$ & \\
\hline & D & 0,02 & $(0,03 ; 0,03)$ & 0,03 & $(0,01 ; 0,05)$ & $(-1,06 ; 1,20)$ \\
\hline \multirow[t]{3}{*}{$\omega 6 / \omega 3$} & C & 1,96 & $(1,88: 2,02)$ & 0,15 & $(0,08: 0,25)$ & \\
\hline & $L$ & 2,23 & $(2,10 ; 2,35)$ & 0,12 & $(0,07 ; 0,29)$ & \\
\hline & D & 0,268 & $(0,20: 0,30)$ & 0,14 & $(0,10 ; 0,25)$ & $(-0,50 ; 0,21)$ \\
\hline
\end{tabular}

\footnotetext{
1 - Quando significativo, o valor é identificado com ${ }^{* *} . \mathrm{G}=$ grupo; Bootstrap $=10000$ reamostragens. $\mu=$ média; DP = Desvio Padrão; IC = Intervalo de confiança; $A G P I=$ ácidos graxos poliinsaturados; AGS = ácidos graxos saturados; $\omega 6=$ Omega $6 ; \omega 3=$ Omega 3 .
} 
MORAES, G.V. et al. Desenvolvimento corporal, avaliações de carcaça e lipedimia de caprinos machos alimentados com grão de linhaça na dieta. PUBVET, Londrina, V. 8, N. 10, Ed. 259, Art. 1718, Maio, 2014.

Os dados de lipídeos totais encontrados nas carcaças desta pesquisa assemelham-se aos de Marinova et al. (2001), que não encontraram diferenças entre as dietas sem adição de óleo e com adição de óleo de girassol na alimentação de caprinos em que a dieta continha os valores médios de $20,25 \%$ de proteína e 1,94\% de lipídios. Russo et al. (1999) encontraram 20,55\% de proteína e $2,71 \%$ de lipídios, no músculo Longissimus dorsi de cordeiros alimentados com dietas contendo 5\% de óleo de milho e abatidos com 105 dias de idade.

Na presente pesquisa foi observado 1,84\% e 2,07\% de gordura total nos grupos controle e linhaça, respectivamente. Naudé \& Hofmeyr (1981) e Madruga et al. (1999) salientaram que a carne caprina apresenta teores de gordura na carcaça de 2,0\% a 9,0\%, valores considerados baixos. Scislowski et al.(2005) verificaram que a infusão no duodeno altera a composição e distribuição dos lipídeos plasmáticos e aumenta a concentração plasmática de AGPI.

Também, relataram que a sensibilidade dos AGPI plasmáticos a peroxidação é dependente dos níveis plasmáticos de antioxidantes, especialmente a vitamina $E$, um nutriente importante tanto para a saúde dos animais como para a estabilidade dos lipídeos sanguíneos e sua deposição tecidual.

Os caprinos alimentados com dieta controle apresentaram 35,68\% de ácidos graxos saturados e os com linhaça $37,68 \%$, valores considerados elevados e, 7,5 e 7,2\% de ácidos graxos poliinsaturados para os grupos controle e linhaça, respectivamente, valores considerados baixos (Tabela 5). A razão ácidos graxos poliinsaturados/saturados (AGPI/AGS) foi, em média, de 0,20, não apresentando diferenças entre as dietas $(P>0,05)$. Este valor está abaixo do mínimo recomendado pelo Departamento de Saúde Americano (Ludovico, 2002), de 0,45, para uma dieta considerada saudável se for utilizado como única fonte de gordura da dieta. O valor encontrado neste estudo é equivalente ao obtido por Rowe et al. 
MORAES, G.V. et al. Desenvolvimento corporal, avaliações de carcaça e lipedimia de caprinos machos alimentados com grão de linhaça na dieta. PUBVET, Londrina, V. 8, N. 10, Ed. 259, Art. 1718, Maio, 2014.

(1999), Russo et al. (1999) e Martins Junior (2000), todos trabalhando com cordeiros da mesma faixa etária, recebendo dietas semelhantes.

A razão $\omega 6 / \omega 3$ variou de 1,96 para o grupo controle e de 2,23 para o grupo linhaça, o que está de acordo com as orientações do Departamento de Saúde Americano (Ludovico, 2002) que recomendam razão 4,0, no máximo, para uma dieta saudável. O desbalanço de ácidos graxos $\omega 6 / \omega 3$ tem sido associado ao elevado risco de doenças cardiovasculares, diabetes e câncer (Williams, 2000).

Os resultados desta pesquisa colocam a carne dos caprinos como uma boa opção para a saúde, pois diversas dietas têm sido feitas usando diferentes espécies e raças, bem como várias fontes de AGPI com o objetivo de melhorar a razão de ácidos graxos poliinsaturados em relação a ácidos graxos saturados, bem como da razão de ácidos graxos $\omega 6 / \omega 3$, procurando-se alcançar os valores recomendados para AGPI/AGS maior que 0,7 e para razão $n-6 / n-3$ menor que 5 (Raes et al., 2004), o que foi encontrado neste trabalho para $\omega 6 / \omega 3$, porém a razão AGPI/AGS ficou abaixo $(0,21$ e 0,19 para grupos controle e linhaça, respectivamente), fato também observado por Cooper et al. (2004), trabalhando com ovelhas, Scollan et al. (2004), trabalhando com bovinos.

A conversão alimentar de $7,92 \mathrm{~kg}$ e 9,4 kg de consumo de alimento por $\mathrm{kg}$ de peso adquirido (Tabela 6), para os grupos linhaça e controle obtido neste trabalho foi similar aos $9,6 \mathrm{~kg}, 8,4 \mathrm{~kg}$ e $7,0 \mathrm{~kg}$ encontrados por Alves et al. (2002), utilizando ovinos Santa Inês terminados em confinamento, recebendo diferentes níveis de energia $(2,42 ; 2,66$ e 2,83 Mcal de EM/kg de MS).

O Grupo linhaça teve uma conversão alimentar melhor que o grupo controle $(P<0,05)$, proporcionando, possivelmente, pelos níveis de extrato etéreo mais elevado neste grupo. Análise econômica deve ser feita para verificar o custo benefício do seu uso ou não com objetivos de melhorar a eficiência de a conversão alimentar em animais confinados. 
MORAES, G.V. et al. Desenvolvimento corporal, avaliações de carcaça e lipedimia de caprinos machos alimentados com grão de linhaça na dieta. PUBVET, Londrina, V. 8, N. 10, Ed. 259, Art. 1718, Maio, 2014.

TABELA 6. Teste $t$ e teste $F$ para verificação de igualdade de médias e para verificação de igualdade de variância média da conversão alimentar dos caprinos alimentados com grão de linhaça e dieta controle

\begin{tabular}{lcccc}
\hline \multirow{2}{*}{ Variável } & \multicolumn{2}{c}{ Dietas } & & \\
\cline { 2 - 5 } & \multicolumn{2}{c}{ Controle Linhaça } & Teste t (P-Valor) & Teste F (P-Valor) \\
\hline Conversão alimentar $(\mathrm{kg})$ & 7,92 & 9,4 & 0,28 & 0,41 \\
\hline
\end{tabular}

P-valor $>0,05$ (Iguais); P-valor $<0,05$ (Desiguais)

\section{Conclusões}

Conclui-se que a inclusão de 9,5\% de semente de linhaça na MS da dieta de caprinos machos não influiu na composição química e de ácidos graxos do músculo Longissimus dorsi, nem alterou o perfil de ácidos graxos de forma desejável em relação aos índices nutricionais (AGPI/AGS e $\omega 6 / \omega 3$ ) para a saúde humana; as quantidades totais de ácidos graxos poliinsaturados, monoinsaturados e saturados no músculo Longissimus dorsi não foram influenciados pelas dietas; não houve alteração nos níveis de colesterol e frações, exceção aos níveis de VLDL e triglicerídeos, bem como nas taxas de rendimento de carcaça entre as dietas.

\section{Agradecimentos}

Os autores agradecem ao $\mathrm{CNPq}$, pelo suporte financeiro para $\mathrm{o}$ desenvolvimento da presente pesquisa.

\section{Literatura Citada}

ALVES, K. S.; CARVALHO, F.F.R.; VÉRAS, A.S.C. Efeito dos níveis de energia em dietas sobre o desempenho de ovinos Santa Inês. In: REUNIÃO ANUAL DA SOCIEDADE BRASILEIRA DE ZOOTECNIA, 39., 2002, Recife. Anais... Recife:Sociedade Brasileira de Zootecnia/TecnoMedia , 2002. CD-ROM.

BAUCHART, D. Lipid: Absorption and transport in ruminants. Journal of Dairy Science, v. 76, p. 3864-3881, 1993. 
COOPER, S.L.; SINCLAIR, L.A.; WILKINSON, R.G.; HALLETT, K.G.; ENSER, M.; WOOD, J.D. Manipulation of the n-3 polyunsaturated fatty acid content of muscle and adipose tissue in lambs. Journal of Animal Science, v. 82, p. 1461-1470, 2004.

DEMEYER, D.; DOREAU, M. Targets and procedures for altering ruminant meat and milk lipids. Proceedings of the Nutrition Society, n, v.58, p.593-607, 1999.

DAVISON, A. C.; HINKLEY, D. V. Bootstrap methods and their applications. Cambridge, New York: Cambridge University Press, 1997. 134 p.

EFRON, B.; TISHIRANI, R. An introduction to the bootstrap. USA:Chapman and Hall, 1993. 85 p.

GEAY, Y.; BAUCHART, D.; HOCQUETTE, J.F. CULIOLI, J. Effect of nutritional factors on biochemical, structural and metabolic characteristics of muscles in ruminants, consequences on dietetic value and sensorial qualities of meat. Reproduction Nutrition Development, v.41, p.126, 2001.

GLIMP, H.A. Meat goat production and marketing. Journal of Animal Science, v. 73, p. 291295, 1995.

HARRISON, F.A.; LEAT, W.M.F.; FOSTER, A. Absorption of maize oil infused into the duodenum of the sheep. Proceedings of Nutrition Society, v. 33, p. 103, 1974.

JENKINS, T.C. Lipid metabolism in the rumen. Journal of Dairy Science, v.76, p.3851-3863, 1993.

KINSELLA, J.E.; SHIMP, J.L.; MAI, J. WEIHRAUCH, J. Fatty acid content and composition of freshwater finfish. Journal of the American Oil Chemists' Society, v. 54, p. 424-429, 1977.

LUDOVICO, A. Concentração de ácido graxo linoléico conjugado (CLA) no tecido adiposo e muscular de bovinos no modelo biológico superprecoce. Botucatu: Universidade Estadual Paulista - Faculdade de Medicina Veterinária e Zootecnia, 2002. 65p. Tese (Doutorado em Zootecnia) - Faculdade de Medicina Veterinária e Zootecnia - Universidade Estadual Paulista, 2002.

MADRUGA, M.S.; ARRUDA, S.G.B.; NASCIMENTO, J.A. Castration and slaughter age effects on nutritive value of the "mestiço" goat meat. Meat Science, v. 52, n. 2, p. 199-125, 1999.

MARINOVA, P.; BANSKALIEVA, S.; ALEXANDROV, S.; TZVETKOVA, V.; STANCHEV, H. CarcasS composition and meat quality of kids fed sunflower oil supplemented diet. Small Ruminants Research, v. 42, p. 219-227, 2001.

MARTINS JUNIOR, A.C. Efeito da variação do peso de abate sobre a composição do músculo longissimus dorsi de cordeiros terminados em confinamento. Maringá, PR: Universidade Estadual de Maringá, 2000. 52p. Dissertação (Mestrado em Química) - Universidade Estadual de Maringá, 2000.

MATTOS, R.; STAPLES, C.R.; THATCHER, W.W. Effects of dietary fatty acids on reproduction in ruminants. Reviews of Reproduction, v. 5, p. 38-45, 2000.

MIR, Z.; RUSHFELD, M.L.; MIR, P.S. PATERSON, L.J.; WESELAKE R.J. Effect of dietary supplementation with either conjugated linoleic acid (CLA) or linoleic acid rich oil on the CLA content of lambs tissues. Small Ruminants Research, v. 36, p.25-31. 2000. 
MODESTO, E. C.; SANTOS, G.T.; VILELA, D.; GONÇALVES, G.D.; MAKOTO, M. Efeitos nutricionais e metabólicos de dietas ricas em ácidos graxos poliinsaturados para os ruminantes e os benefícios para o homem. Arquivos de Ciências Veterinárias e Zoologia da Unipar, v. 5, n. 1, p. 119$134,2002$.

NAUDÉ, R.T.; HOFMEYR, H.S. Meat production, goat production. London: Academic Press, 1981. $467 \mathrm{p}$.

NATIONAL RESEARCH COUNCIL (NRC). Nutrient requirements of goat: Angora, dairy and meat goats in temperate and tropical countries. Washington : National Academic Press, 1981. 99p.

RAES, K.; SMET, S.DE ; DEMEYER, D. Effect of dietary fatty acids on incorporation of long chain polyunsaturated fatty acids and conjugated linoleic acid in lamb, beef and pork meat: a review. Animal Feed Science and Technology, v. 112, p. 199-221, 2004.

REIS, W.; JOBIM, C.C.; MACEDO, F. A. F. Características de carcaça de cordeiros alimentados com dietas contendo grãos de milho conservados em diferentes formas. Revista Brasileira de Zootecnia, v. 30, n.4, p.1308-1315. 2001.

ROWE, A.; MACEDO, F. A. F.; VISENTAINER, J.V.; SOUZA, N. E.; MATSUSHITA, M. Muscle composition and fatty acid profile in lambs fattened in drylot or pasture. Meat Science, v.51, p.283-288, 1999.

RUSSO, C.; PREZIUSO, G.; CASAROSA, L. et al. Effect of diet energy source on the chemicalphysical characteristics of meat and depot fat of lams carcasses. Small Ruminants Research, v.33, p.77-85, 1999.

SAÑUDO, C.; SIERRA, I. Calidad de la canal en la especie ovina. Ovino, v.11, p.127-157, 1986.

SANZ, M.; LOPES, B. C. J.; MENOYO, D. et al. Abdominal fat deposition and fatty acid synthesis are lower and $\beta$-oxidation is higher in broiler chickens fed diets containing unsatured rather than satured fat. Journal of Nutrition, v.30, p. 3034-3037, 2000.

SCISLOWSKI, V.; BAUCHART, D.; GRUFFAT, D. et al. Effects of dietary n-6 or n-3 polyunsaturated fatty acids protected or not against ruminal hydrogenation on plasma lipids and their susceptibility to peroxidation in fattening steers. Journal of Animal Science, v. 83, p. 2162-2174, 2005.

SCOLLAN, N.D.; CHOI, N.J.; KURT, E. et al. Manipulating the fatty acid composition of muscle and adipose tissue in beef cattle. British Journal of Nutrition, v. 85, n. 1, p. 115-124, 2001.

SILVA, D.J. Analise de alimentos: métodos químicos e biológicos. 2. ed., Viçosa: Universidade Federal de Viçosa, 1990. 166 p.

USDA - DEPARTMENT OF AGRICULTURE. Food composition standard release. USA: Fed. Ed., 1998. 324 p.

VELAZQUEZ, L.F.U. Concentrações séricas de progesterona e colesterol em cabras mestiças alimentadas com dietas hiperlipídicas no início da gestação. Revista da Sociedade Brasileira de Zootecnia, v. 25, n. 5, p. 1017-1025, 1996.

VOEDINGSAANBEVELINGEN, VOOR B. De Hoge Gezondheidsraad. Ministerie van Sociale zaken. Volksvertegenwoordigers en Leef, p. 81-86, 2000.

WILKINSON, J. M.; STARK, B. A. Profitable meat. In: WILKINSON, J. M.; STARK, B. A. (Ed.)

Comercial goat production. Chapter 10. p. 39. Oxford: BSP Profissional Books. 170 p. 1987.

WILLIAMS, C. M. Dietary fatty acids human health. Nutrition Animal, v.49, p.165-180, 2000. 
YAMAMOTO, S. M. Desempenho, digestibilidade e características de carcaças de cordeiros, terminados com dietas contendo diferentes óleos vegetais. Maringá, PR: Universidade Estadual de Maringá, 2003. 88 p. Dissertação (Mestrado em Zootecnia), Universidade Estadual de Maringá, 2003.

ZAIN, M.J. Role of fatty acids in adipocyte growth and development. Journal of Animal Science, v. 82, p. 916-924, 2004.

ZEOULA, N.M.B.L. Influência da alimentação nas características quantitativas da carcaça e qualitativas da carne de cordeiros Morada Nova. Jaboticabal, SP: Faculdade de Ciências Agrárias e Veterinárias- UNESP, 2002. 65p. Dissertação (Mestrado em Zootecnia) - Faculdade de Ciências Agrárias e Veterinárias/Universidade Estadual Paulista, 2002. 